\title{
DIGITAL TOOLS FOR DOCUMENTING AND CONSERVING BAHRAIN'S BUILT HERITAGE FOR POSTERITY
}

\author{
D. Mezzino ${ }^{\text {a }}$, L. Barazzetti ${ }^{\text {b }}$, M. Santana Quintero ${ }^{\text {c }}$, A. El-Habashi ${ }^{d}$ \\ ${ }^{a}$ Carleton Immersive Media Studio (CIMS), 1125 Colonel by Drive, Ottawa, On, K1S 5B6 Canada, \\ Interuniversity Department of Regional and Urban Studies and Planning (DIST), Politecnico di Torino, Via Sant'Ottavio, 20,10122 - \\ Torino, Italy, davide.mezzino@gmail.com \\ b ABC Department, Politecnico di Milano, Via Ponzio, 3120133 - Milan, Italy, luigi.barazzetti@polimi.it \\ c Carleton Immersive Media Studio (CIMS), 1125 Colonel by Drive, Ottawa, On, K1S 5B6 Canada, Mario.santana@ carleton.ca \\ dArchaeology \& National Heritage Directorate, Manama, Bahrain, alaa.elhabashi@culture.gov.bh
}

KEY WORDS: Digital Workflows, Heritage Conservation, Management, IT Documentation, Built Heritage, Bahrain, 3D Imaging, Photogrammetry, Rectifying Photography, Total Station, Computer-Aided Drawing.

\begin{abstract}
:
Documenting the physical characteristics of historic structures is the first step for any preventive maintenance, monitoring, conservation, planning and promotion action. Metric documentation supports informative decision-making process for property owners, site managers, public officials, and conservators. This information serves also a broader purpose, over time, it becomes the primary means by which scholars, heritage professionals, and the general public understand a site that radically changed or disappeared. Further, documentation supports monitoring as well as the character-defining elements analysis, relevant to define the values of the building for the local and international community. The awareness of these concepts oriented the digital documentation and training activities, developed between 2016 and 2017, for the Bahrain Authority for Culture and Antiquities (BACA) in Bahrain. The developed activities had two main aims: a) support the local staff in using specific recording techniques to efficiently document and consequently preserve built heritage sites with appropriate accuracy and in a relatively short period; b) develop a pilot project in collaboration with BACA to validate the capacity of the team to accurately document and produce measured records for the conservation and management of Bahrain built heritage. The documentation project has been developed by a multidisciplinary team of experts from BACA, Carleton Immersive Media Studio (CIMS), Carleton University, Canada and a contracted researcher from the Gicarus Lab, Politecnico di Milano (POLIMI) in Italy. In the training activities, the participants have been exposed to a wide range of recording techniques, illustrating them the selection criteria for the most suitable one, according to requirements, site specifications, categories of values identified for the various built elements, and budget. The pilot project has been tested on three historical structures, both with strong connotations in the Bahrain cultural identity: the Shaikh Isa bin Ali house, Aljazzaf house and the Siyadi Majlis. These two buildings, outstanding examples of Bahrain architecture as well as tangible memory of the country history, have been documented employing several digital techniques, including: aerial and terrestrial photogrammetry, rectifying photography, total station and 3D laser scanning.
\end{abstract}

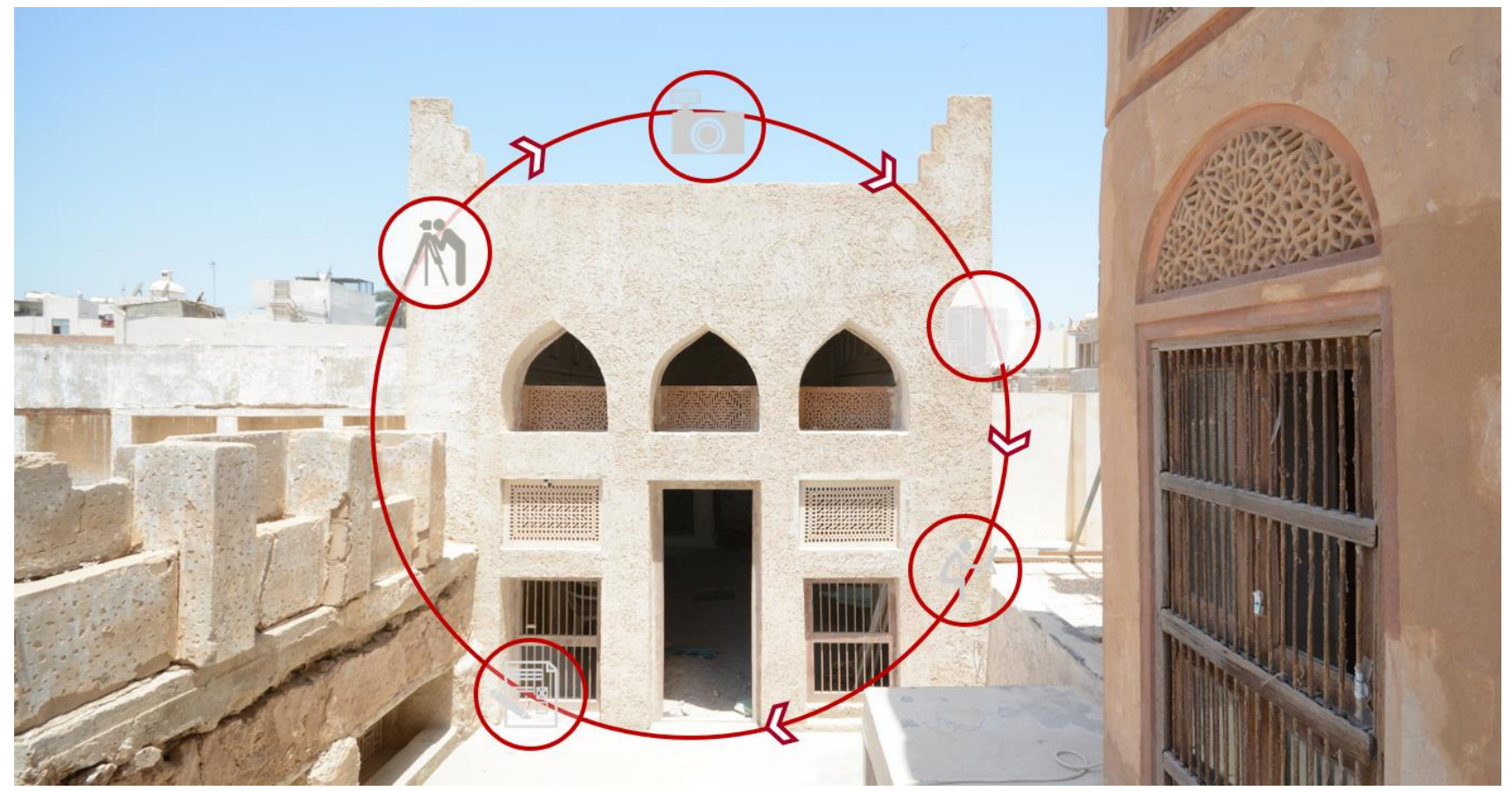

Figure 1 Siyadi Majlis, Muharraq, Bahrain. Image source: Davide Mezzino. 


\section{INTRODUCTION}

Recording the physical characteristics of historic structures and landscapes is a cornerstone of preventive maintenance, monitoring, and conservation. The information produced by such work assists the decision-making process for property owners, site managers, public officials, and conservators. Rigorous documentation may also serve a broader purpose: over time, it becomes the primary means by which scholars and the public understand a site that has since radically changed or disappeared. These records also serve as posterity and monitoring records in the event of catastrophic or gradual loss of the heritage resource.

In line with these considerations, the proposed approach and workflow adopted for the conservation of Bahrain built heritage were mainly oriented by two aims:

- Support the local staff with the use of specific recording techniques to document and therefore preserve Bahrain historic structures with appropriate accuracy and in a relatively short period.

- Conduct a pilot project in collaboration with the Bahrain Authority for Culture and Antiquities (BACA) to validate the capacity of the team to accurately document and produce measured records for informative conservation actions of Bahrain built heritage.

The project was conducted by a multidisciplinary team of experts from Carleton Immersive Media Studio (CIMS) and a contracted professional from the Politecnico di Milano (Polimi) in Italy.

\subsection{Framework of the documentation activities: the Pearling project}

The capacity-building activities and documentation strategies were developed in the wider framework or the so-called Pearling ${ }^{1}$ Initiative. The project financed by the Islamic Development Bank (IDB) for a total amount of US $\$ 48$ million (Economist Newspaper, n.d.), aims at supporting the conservation and rehabilitation of the urban areas ${ }^{2}$ of the city of Muharraq, Bahrain, connected with the pearling economy.

Within this framework, the Project involves the rehabilitation and conservation of twelve historical buildings, listed in the Pearling, Testimony of an Island Economy UNESCO site, inscribed on the World Heritage List in 2012 (UNESCO, n.d.). These properties along with the walking trail of $3.5 \mathrm{~km}$ and some additional buildings and public spaces, connected with the Muharraq's pearling heritage, are currently the object of conservation, upgrading, and renovation (Bahrain Authority for Culture and Antiquities, n.d.). Within this framework, the relevance of proper documentation strategies for informed conservation or renovation actions appears evident.

\footnotetext{
${ }^{1}$ The Pearling is an outstanding example of a traditional sea-use which shaped the local economy and cultural identity. This secular practice is one of the most significant example of a natural pearl-collection tradition and is based on the Arabian Gulf oyster beds north of Bahrain. Despite the market associated with the pearling activity decrease exponentially to several factors (from the diffusion of the cultured pearls through artificial injections in the 1930s to the economic change in Bahrain brought by the discovery of oil in the 1932) many features and practices still survive. The historic structures of Muharraq are the evidence of this traditional sea-use and its related economy. These include residential and commercial buildings, tangible examples of the historical cultural and socio-economic context associated with the pearling society. These
}

\subsection{Historic, territorial and socio-cultural framework}

Muharraq is located on the north-east side of the Bahrain Island in the Arabian Gulf, at an altitude of $13 \mathrm{~m}$, a latitude of 26,2572 $\left(2615^{\prime} 25.920 " \mathrm{~N}\right)$ and a longitude of 50,6119 (5036'42.840"E) (TipTopGlobe.com, n.d.).

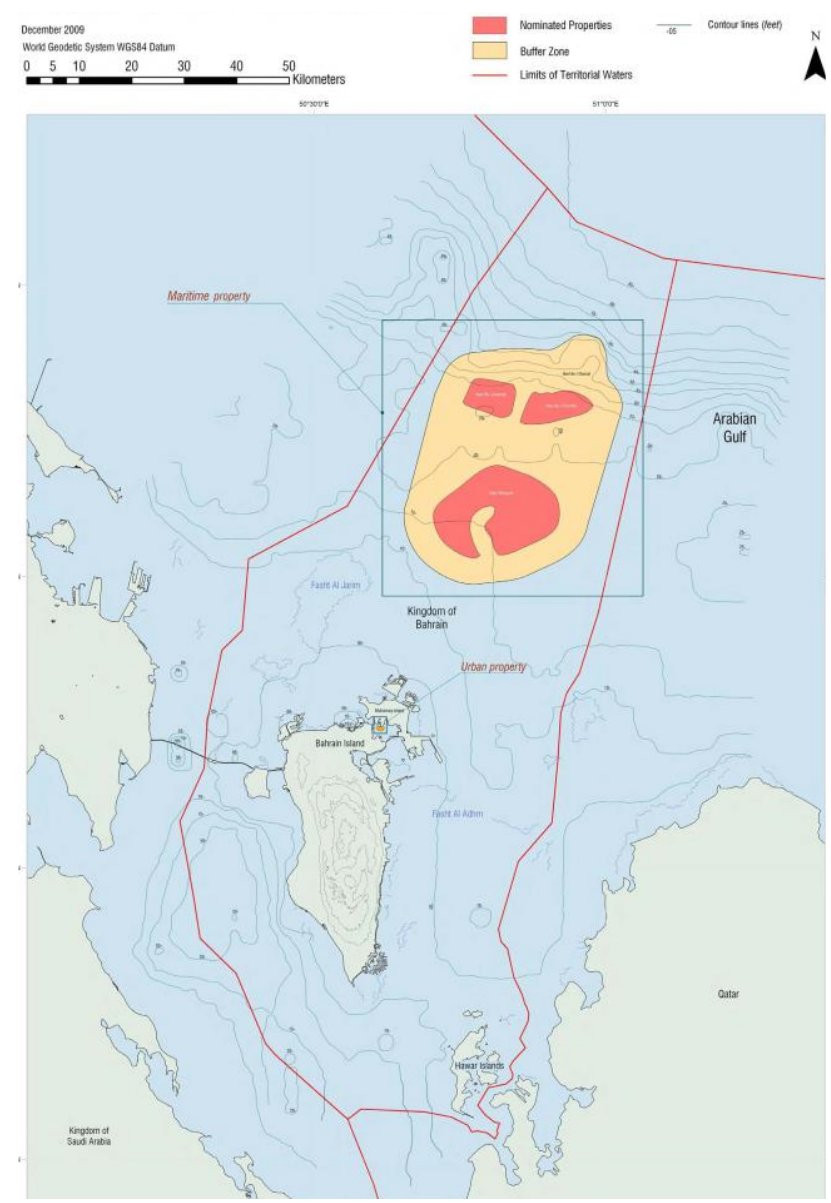

Figure 2 Map showing the location of Bahrain and its territorial waters in the Arabian Gulf as well as the core and the buffer zone of the Pearling, Testimony of an Island Economy UNESCO site. Image source (Kingdom of Bahrain Ministry of Culture \& Information, 2012).

The site development was characterized by the pearling cultivation shaping the local economy, the urban and architectural context as well as the social one.

Pearls cultivation is deeply rooted in Bahrain history since the Neolithic under the Dilmun civilization. During the Roman Empire, pearls were cultivated and traded and Bahrain developed an organized pearling industry (Kingdom of Bahrain Ministry of Culture \& Information, 2012).

historic structures, developed within the pearling socio and economic phenomena, also embed intangible values including, but not limited to, social hierarchies, legal systems, songs, stories, poetry, festivals and dances. The built heritage associated with the pearling economy is also representative of the traditional uses and functions of these buildings and related specific building techniques and design (Kingdom of Bahrain Ministry of Culture \& Information, 2012).

2 This operation is intended to support the local development, fostering socio-economic as well as cultural growth, by improving, for instance, living conditions of residents, developing new commercial activities and improving urban mobility (Economist Newspaper, n.d.) 
This trend expanded and consolidated in the medieval period reaching its apex between the XVIII and XIX century when the global demand of pearls (mainly from Europe) grew exponentially strongly affecting Bahrain economic growth and territorial developments in terms of infrastructure and services associated with the pearling market. In this framework, Muharraq became the main pearl-diving settlement in Bahrain.

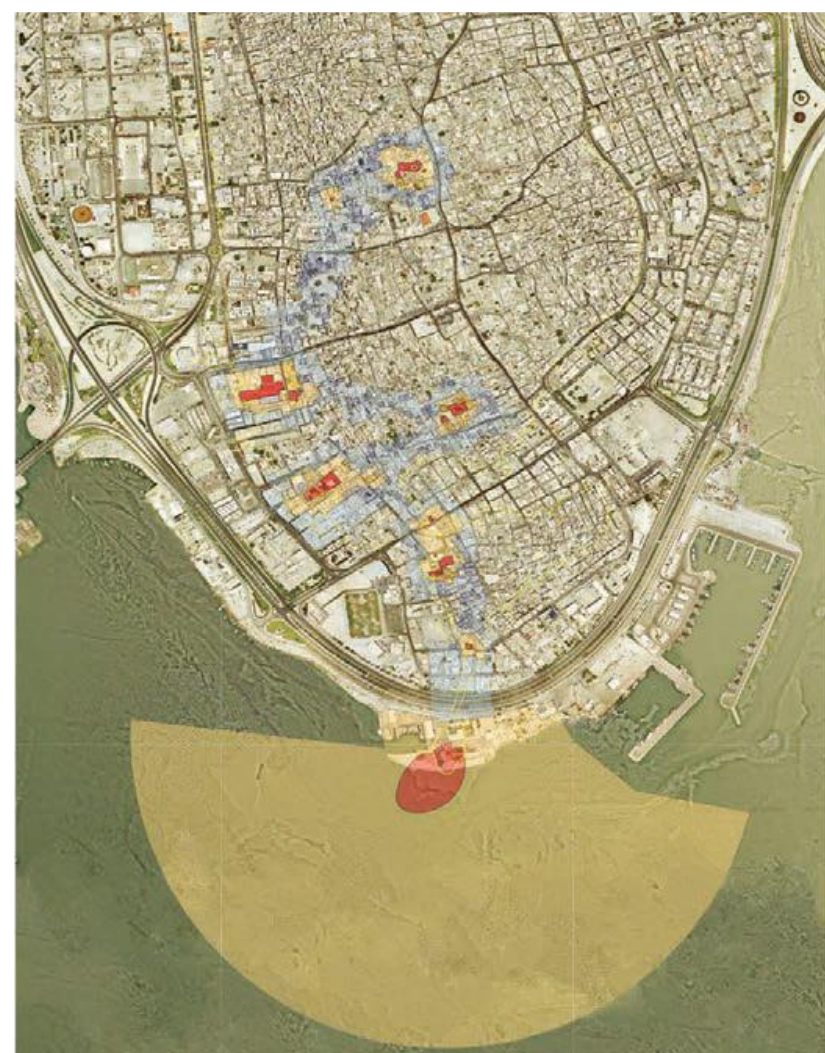

Figure 3 Map of the Muharraq inscribed properties and their buffer zone. Image source (Kingdom of Bahrain Ministry of Culture \& Information, 2012).

\begin{tabular}{|c|c|c|c|c|}
\hline Itame of propenty & Longitude & Latitude & UTM Easting & Urm llorthing \\
\hline Hayr Bü--Thămah & $50^{\circ} 544284^{\prime} \mathrm{E}$ & $26^{6} 4725.44 \mathrm{~N}$ & 491243.3 & 2963224.3 \\
\hline Hayr Bü 'Amämah & $50^{\circ} 48^{1} 13.14^{\prime} \mathrm{E}$ & $26^{6} 4827.036^{\prime} \mathrm{N}$ & 480486.4 & 2965131 \\
\hline Hayr Shtayyah & $50^{\circ} 48.55 .836^{\circ} \mathrm{E}$ & $26^{\prime} 3640.896^{\prime} \mathrm{N}$ & 481633.8 & 2943404.9 \\
\hline Bü Măhir Seashore & $50^{\circ} 3647.916^{\circ} \mathrm{E}$ & $26^{\circ} 1426.952^{2} \mathrm{~N}$ & 461421.2 & 2902397 \\
\hline Qaatat Bü Măhir & $50^{\circ} 36^{\prime} 48.636^{\prime} \mathrm{E}$ & $26^{\circ} 1428.608^{\prime} \mathrm{N}$ & 461441.1 & 2902448 \\
\hline Al-Ghûș House & $50^{\circ} 3651.084^{\prime} \mathrm{E}$ & $26^{\prime} 1438.364^{\circ} \mathrm{N}$ & 461510 & 2902748 \\
\hline Badr Ghulum House & $50^{\circ} 3648.348^{\circ} \mathrm{E}$ & $26^{\prime} 14444.592^{2} \mathrm{~N}$ & 461434.8 & 2902940 \\
\hline Al.Jalahma House & $50^{*} 36^{\prime} 49.14^{\prime} E$ & $26^{\circ} 1445.528^{\prime} \mathrm{N}$ & 461456.9 & 2902969 \\
\hline Al-AlawiHouse & $50^{\prime} 3647.808^{\circ} \mathrm{E}$ & $26^{\circ} 14499.2 \mathrm{~N}$ & 461420.2 & 2903082 \\
\hline Fakhro House & $50^{\prime} 3638.592^{\prime} \mathrm{E}$ & $26^{\circ} 1451.9 \mathrm{~N}$ & 461165.2 & 2903165 \\
\hline Murad House & $50^{\circ} 36^{4} 48.996^{\circ} \mathrm{E}$ & $26^{\circ} 1458.632 \mathrm{~N}$ & 461485.9 & 2903371 \\
\hline Murad Majlis & $50^{\prime} 36^{4} 48.996^{\circ} \mathrm{E}$ & $26^{\circ} 1457.696^{\prime} \mathrm{N}$ & 461454.4 & 2903343 \\
\hline Slyadi Shops & $50^{\circ} 3636.216^{\prime} \mathrm{E}$ & $26^{1} 1459.784^{\prime} \mathrm{N}$ & 461100.1 & 2903408 \\
\hline Amärat Yousiff A. & $50^{\circ} 3633.156^{\prime} \mathrm{E}$ & $26^{\circ} 1459.892^{2} \mathrm{~N}$ & 461014.6 & 2903412 \\
\hline Amârat All Rashed Fakhro (1) & $50^{\prime} 366^{3} 4.38^{\prime} \mathrm{E}$ & $26^{4} 150.612^{2} \mathrm{~N}$ & 461048.7 & 2903434 \\
\hline 'Amärat All Rashed Fakhro (II) & $50^{\prime} 3633.912^{2} \mathrm{E}$ & $26^{1} 15^{\circ} 1.224^{\mathrm{N}} \mathrm{N}$ & 461036.1 & 2903452 \\
\hline Nükhidhah House & $50^{\prime} 3639.42^{\prime} \mathrm{E}$ & $26^{\prime} 15^{\prime 1} 16.488^{\prime} \mathrm{N}$ & 461190 & 2903922 \\
\hline Slyadi House & $50^{\prime} 36^{4} 46.404^{\prime} \mathrm{E}$ & $26^{\circ} 15^{\prime 19} \cdot 332^{2} \mathrm{~N}$ & 461384.4 & 2904009 \\
\hline Slyadi Majlis & $50^{\circ} 36^{\prime} 45.396^{\circ} \mathrm{E}$ & $26^{\circ} 15^{19} 19.296^{7} \mathrm{~N}$ & 461356.1 & 2904007 \\
\hline Siyadi Mosque & $50^{\circ} 3645.072^{2} \mathrm{E}$ & $26^{\prime} 15^{\prime} 18.612^{2} \mathrm{~N}$ & 461346.9 & 2903987 \\
\hline
\end{tabular}

Figure 4 List of the 17 architectural structures listed in the World Heritage List in 2012. Image source (Kingdom of Bahrain Ministry of Culture \& Information, 2012) adapted by the author.

\footnotetext{
${ }^{3}$ According with the UNESCO Convention (1972), article 1, the site is
} composed of 2 groups of buildings, 9 monuments and 4 sites.
Therefore, Pearling is a testimony of the Bahrain economy. The site is a serial nomination including 15 sites (11 architectural properties; 3 marine sites, oyster beds, located in the northern territorial waters of the island and one seashore area in the south of the Muharraq city, in the northeast of the island) ${ }^{3}$. The activities focused on the 11 architectural properties, including 17 architectural structures, located in the Muharraq urban area.

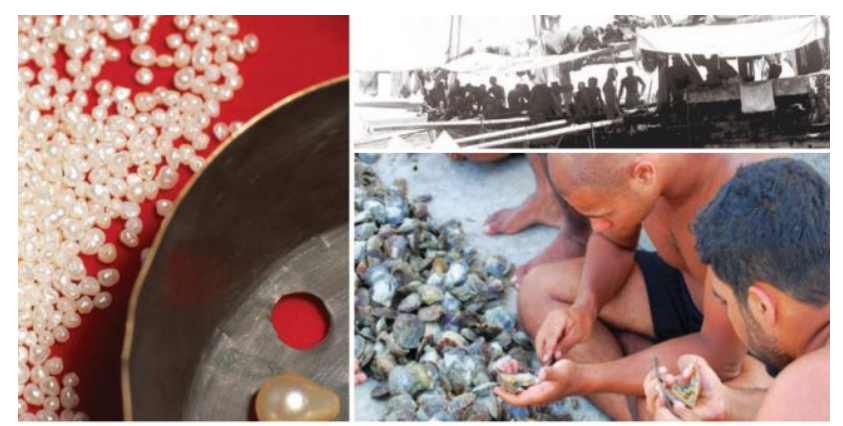

Figure 5 Images illustrating different phases associated with the pearling cultivation. Image source (Kingdom of Bahrain Ministry of Culture \& Information, 2012).

\subsection{Capacity building for local professionals}

The developed capacity building activity had two main aims:

- Acquaint participants with a wide range of recording techniques and tools to help Bahrain Authority for Culture and Antiquities (BACA) staff decide which techniques are best suited, according to heterogeneous sites and objectives.

- Disseminate information, knowledge, and skills in built heritage documentation strategies.

Addressing these aims, capacity-building activities consisted of theoretical as well as practical training.

Capacity building activities included a preparatory phase for the development of protocols and guidelines as well as three missions to Bahrain for on the field training activities.

After completing the preparation of protocols and datasets, the training course was carried out at the Bahrain Authority for Culture and Antiquities (BACA) offices and in two selected historic architectural complexes in the Muharraq urban area, testing documentation workflows, techniques, and tools.

The capacity-building activities were related to digital documentation techniques to record color, shape, geometry, assess conditions and identify character-defining elements (D. Mezzino, Quintero, Pwint, Latt, \& Rellensmann, 2016) of Bahrain built heritage.

Theoretical and practical lessons were carried out to explain the procedures for data acquisition and processing, with a special attention to the requirements of the project (i.e. the need of accurate and reliable measuring tools to capture the geometry of the buildings to be restored). Lessons had two aims: to train participants with a wide range of recording techniques and to help the staff decide which techniques are best suited. Each of the three mission was five days long.

Within these three missions, intensive sessions in which different instruments and techniques were explained and applied in the 
field were carried out after introducing basic concepts on cultural heritage documentation. After that, the following recording techniques were explained:

- Total station: the work consisted in explaining the basic concepts and the measurement principle based on distance and angle measurements, converted into XYZ coordinates (Barazzetti, Banfi, Brumana, Raffaella Gusmeroli, \& Previtali, Mattia Schiantarelli, 2015). Particular attention was placed to the set up of a network materialized with control points on the ground and targets. The importance of the total station for the definition of a stable reference system was addressed. Participants learned how to set up the total station and start a new project by creating a false origin and a direction (azimuth). The work continued with the case of different station points, i.e. how to move the station to the next point with both the resection and known backsight point techniques, without changing the reference system.

- Rectifying Photography: theoretical and practical lessons were carried out to explain how to measure flat-like objects with digital images. The case of building façades was investigated and discussed. Procedures for image acquisition in the case of long facades were addressed (image mosaicking). Rectification with both analytical methods (integrating total station data) and geometric methods (vertical/horizontal lines with a known width/height ratio) were explained and applied to the façade of the Shaikh Isa bin Ali house, Aljazzaf house and the Siyadi Majlis used as cases study.

- 3D Photogrammetry: an introductory lesson on photogrammetry and image acquisition was carried out to explain the advantages and limitations of this technique. Considerations about the object that can be surveyed/reconstructed via photogrammetry and the recommended overlap were discussed. The importance of suitable configurations (sequences, blocks, mixed configurations) for automated photogrammetric processing was underlined. Digital processing was carried out with the images acquired on site, for both single facades and complete rooms. Images were integrated with total station data to work in a georeferenced system. Aerial photogrammetry demonstration was carried out using a drone to complete the list of the most common digital documentation techniques used in cultural heritage documentation. Participants did not directly use this tool but processed the data coming from it. Aerial photogrammetry demonstration was carried out to show the potential of such method.

In terms of tools instead, the BACA staff has been exposed to several tools. For each tools strengths, potentials, limits and constraints (in terms of training, time and costs) have been outlined. A toolbox assessment has been also provided considering BACA needs and the specificities of Bahrain built heritage. The tools used in the on-field activities are illustrated in section 3.2.

Additionally, to on field data acquisition, employing different techniques, BACA staff has been trained also in the data processing phase.

Agisoft Photoscan has been taught and used to process data (pictures) coming from aerial and terrestrial photogrammetry. Autocad 2016 functionalities have been taught showing how to import, orient and manage a pointcloud in a CAD environment to generate 2D drawings.

Hugin software application has been illustrated to create 360 degree panoramic pictures.
Perspective Rectifier has been showed to rectify images and generate orthophotos.

CloudCompare and Autodesk Recap have been taught to present their opportunities in managing, referencing and combining pointclouds,

In terms of management of the acquired data, Computed Aided Design (CAD) and Building Information Modelling (BIM) systems were also illustrated.

Concerning the use of CAD workflows to produce plans, sections, and elevations, with the data acquired from total station, digital images and photogrammetry, were illustrated.

About BIM, workflows to produce 3D model from pointcloud generated with photogrammetry techniques was described presenting how to orient, manage and model from the pointcloud in a BIM environment.

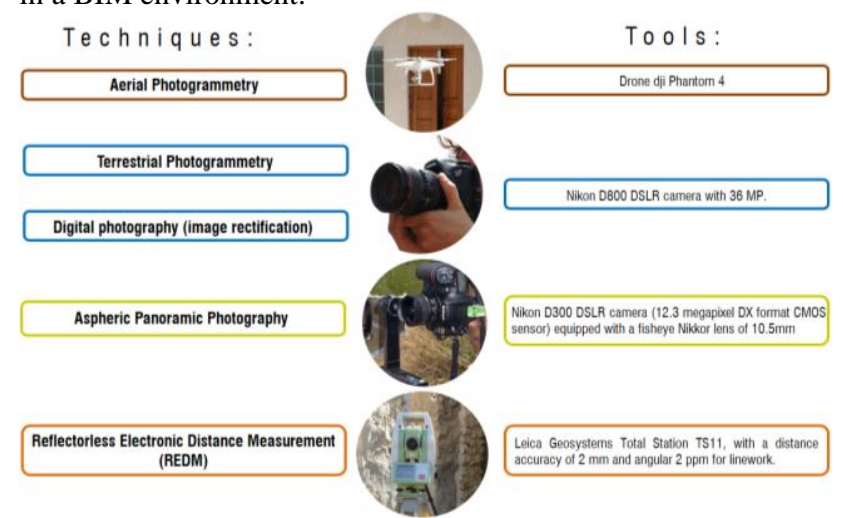

Figure 6 Image showing the used tools associated with each recording technique.

Participants actively participated in both theoretical and practical lessons. They understood the role of digital data collection and processing in historic building restoration and preservation. They tested digital documentation workflows, understating the role of visual documentation, as well as the potential and limitation of such recording tools on three designed heritage properties in Bahrain.

\section{RECORDING STRATEGY}

\subsection{Training activities organization.}

According to the course objectives, the training approach involved a collective collaboration among the different professional profiles of the BACA members. In the training activities the trainee were divided into three main teams.

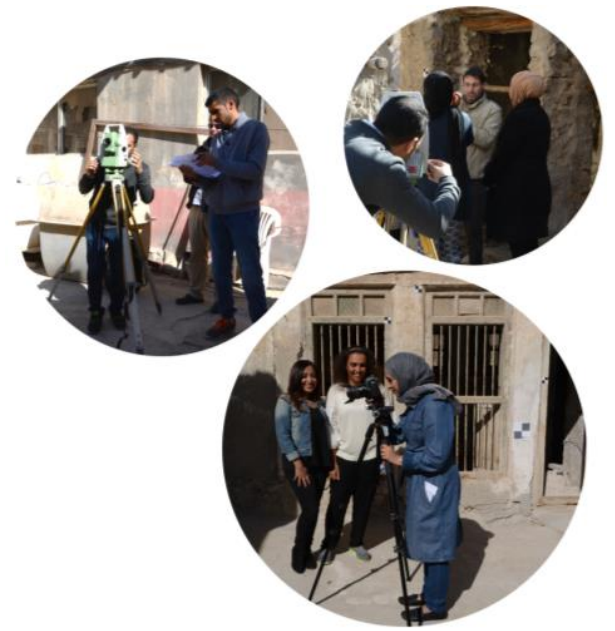

Figure 7 BACA participants during the documentation activities. Images source: Davide Mezzino. 
Each working team acquired and processed data coming from the different employed techniques, generating 3D point cloud models to be used to develop 3D and 2D drawings.

Each team was trained in the use of these documentation techniques to document conditions, shape, color and geometry of Bahrain historic structures.

The teaching strategy involved an innovative role-playing technique, empowering participants and instructors to:

- Develop an understanding of the role of information in conservation, addressing national and international standards;

- Review the potential limitations of recording and documentation techniques, including simple and advanced tools, and the financial constraints.

- Develop a practical approach to the use of these tools and documentation techniques in order to capture information from cultural heritage resources;

- Include the use of information systems in cultural heritage resources management;

- Design reports for presenting information to stakeholders and decision makers.

In order to stimulate the cultural exchange, each team was composed of professionals with different background including engineers, architects, photographers, designers, archaeologists, and conservators.

The work was fieldwork based, supervised by experts from CIMS, Carleton University and Gicarus, Politecnico di Milano.

Each team had the opportunity to use and learn different documentation techniques including:

- Total station survey,

- Field notes and sketches;

- Photogrammetry;

- Site digital photography portfolio, including panoramic photographs;

- 2-dimensional drawing production;

- 3-modelling in a BIM environment.

The capacity-building activities were carried out during three different on the field missions from December 2016 to Aril 2017.

The capacity building activities prepared for the Bahrain Authority for Culture and Antiquities (BACA) provided an overview, tailored made protocols and hands-on training on the most effective techniques that have proven to be appropriate when recording heritage structures.

Different techniques for digital documentation have been explained and used during the practical activities in the three intense working weeks. A complete workflow for digital documentation has been developed to collect accurate metric information and produce deliverables. The production workflow starts from the preliminary planning phase of the survey to the production of measured drawings in AutoCAD, 3D models and digital orthophoto. The workflow and additional recommendations are described in the following sections.

\subsection{Techniques and tools}

In the capacity building activities, techniques illustrated and used included aerial and terrestrial photogrammetry, Reflectorless Electronic Distance Measurement (REDM) (Total Station survey) and Rectify photography.

Techniques mainly employed visual and dimensional tools.
Visual tools were used for photogrammetry, digital photography and rectify photography techniques. These tools included hardware and software components. The first ones included leveled DSLR cameras and a drone. The second ones, used in the data processing phase, included software applications such as Agisoft Photoscan, Perspective Rectifier, Hugin, AutodeskRecap, CloudCompare, Adobe Bridge and Adobe Photoshop.

Dimensional records instead were used for hand recording, and Reflectorless Electronic Distance Measurement (REDM). Tools used included two Total Stations in the data acquisition phase and Autodesk AutoCAD software in the data processing phase.

\section{DIGITAL DOCUMENTATION WORKFLOWS}

\subsection{Planning phase}

The first step in the digital documentation workflow consisted in the definition of the level of detail required for the seventeen architectural structures to be renovated and conserved by the BACA staff (three out of the seventeen structures were used as pilot cases in the capacity-building activity). In this specific case, detailed documentation (scale 1:200 $\mathrm{m}$ to $1: 10 \mathrm{~m}$ ) was required.

Tools selection followed main criteria: operability, portability, precision, range, price, level of engagement robustness and speed.

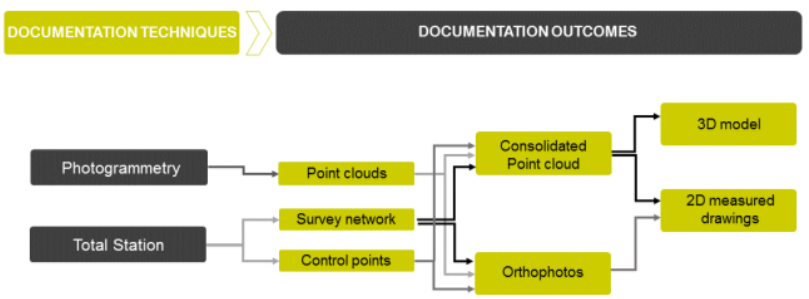

Figure 8 Digital documentation workflow. Image source: Davide Mezzino.

\subsection{Data acquisition}

Data acquisition was carried out through visual and dimensional tools. These included:

- two Leica Geosystems Total Station TS11 with a distance accuracy of $2 \mathrm{~mm}$ and angular $2 \mathrm{ppm}$ for linework also equipped with a mini prism;

- two tripods;

- a drone Phantom 2 Vision +;

- a camera Nikon D800 DSLR camera with 36 MP;

- two cameras Canon 5DS with a $24 \mathrm{~mm}$ lens and a 16-35 mm lens

\subsection{Data processing}

In terms of data processing different software applications and workflows were illustrated.

Image processing included Adobe Bridge, Adobe Photoshop, Perspective Rectifier,

To generate and manage pointcloud coming from aerial and terrestrial photogrammetric data, Agisoft Photoscan, CloudCompare and Autodesk AutoCAD were used.

To generate 2D measured drawings from the pointcloud and orthophots, generated out of it, Computer-aided design (CAD) 
applications, using Autodesk AutoCAD 2016, was illustrated and used.

The training also included a training session on how to develop 3D models from the pointcloud, addressing challenges and limits of 3D semantic modelling in a Building Information Model (BIM) environment, using the Autodesk Revit 2016 software.

\subsection{Outcomes}

The generated outcomes included:

- Protocols, guidelines and specification on built heritage documentation;

- Orthophotos;

- Consolidated pointclouds;

- 2D measured drawings;

- 3D models (in a BIM environment);

- Final report with the planning of the future activities to be carried out, considering BACA human resources, skills and available techniques and tools.
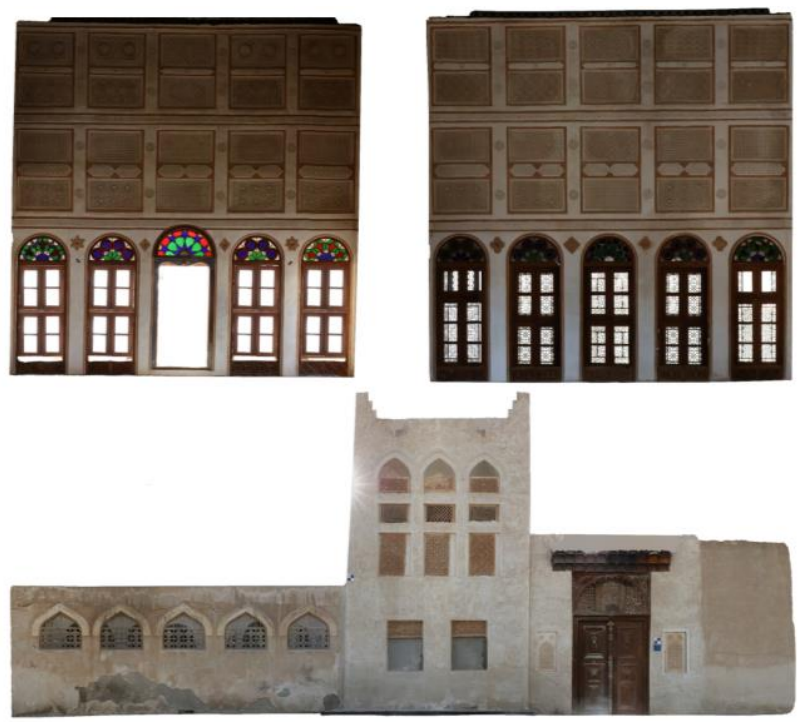

Figure 9 Samples of orthophotos generated from rectified photography and from the point cloud. Software employed Adobe Photoshop, Agisoft Photoscan and Perspective Rectifier. Images source: Authors and BACA staff.
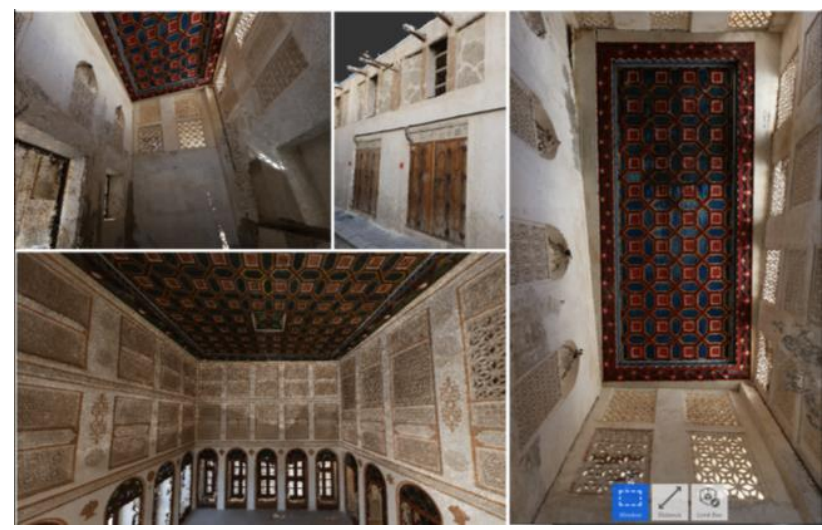

Figure 10 Examples of the developed consolidated pointcloud. Software employed Agisoft Photoscan and Autodesk Recap. Images source: Authors and BACA staff.

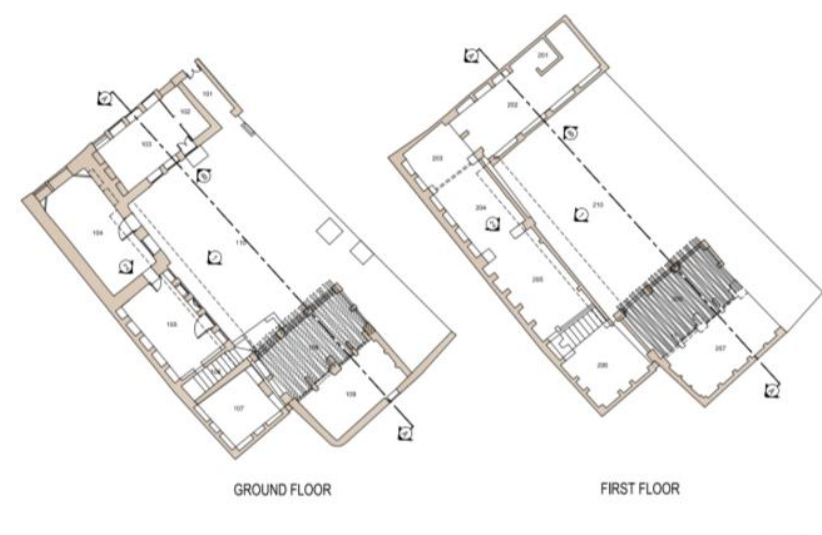

Figure 11 Aljazzaf house flooeplans. Example of generated 2D outcomes. Software employed Autodesk AutoCAD 2016. Images source Authors and Marwa Reyadh Alarayedh.

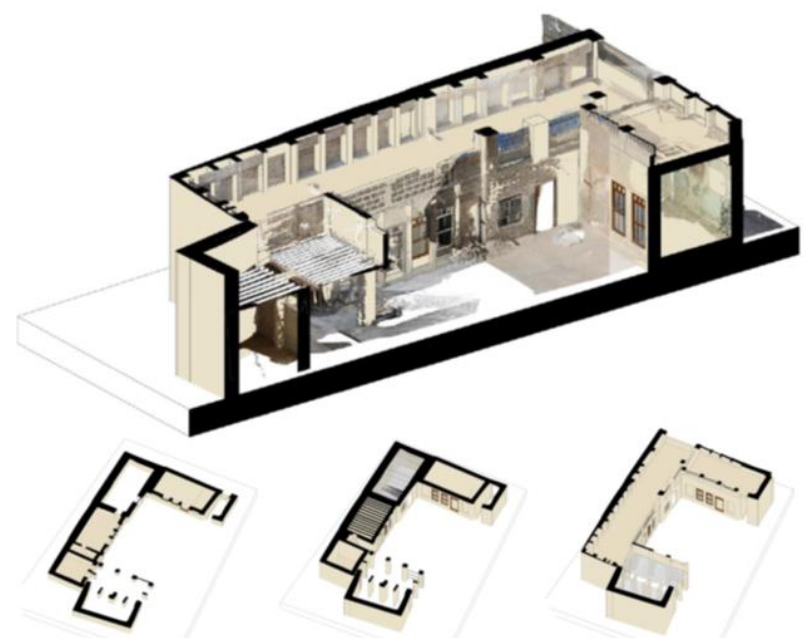

Figure 12 Sectioned views of the BIM model of the Aljazzaf house. The model was generated from the pointcloud. Software employed Autodesk Revit 2016. Images source Authors and Marwa Reyadh Alarayedh.

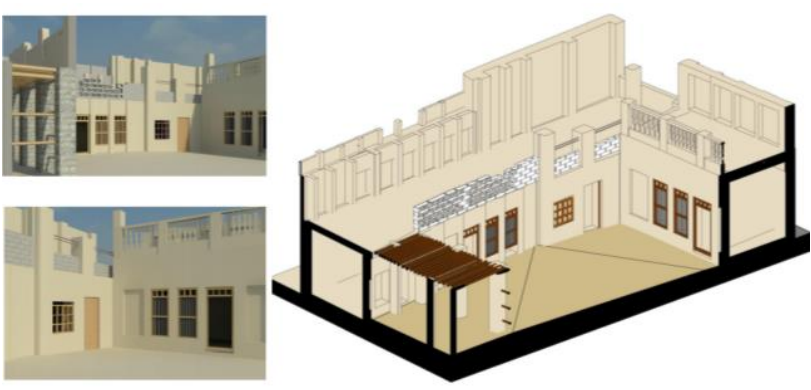

Figure 13 BIM model of the Aljazzaf house developed from the consolidated pointcloud and render samples generated from the BIM model. Software employed Autodesk Revit 2016. Images source Authors and Marwa Reyadh Alarayedh. 


\section{RECCOMENDATIONS AND FUTURE PERSPECTIVES}

Technical recommendations focus on data reliability, longevity and fragmentation.

Concerning information reliability, it is necessary to assure quality and integrity of heritage records. For instance, a criteria to validate the metric quality of the obtained results could be to cross-validate data coming from different recording techniques such as photogrammetry and laser scanning. Additionally, the combination of such records in a reliable survey network, surveyed with a total station, would provide an additional control on the measurements. This becomes even more evident considering the high accuracy level achievable with modern total stations and rigorous adjustment techniques.

Attention should also be paid to data longevity particularly considering the growth of digital records thus increasing longstanding problems. Possible solutions consist in having data structured in a server network easily accessible also for future users not familiar with the adopted workflows. Additionally, metadata description should be included in the server network providing a detailed description of how to use the information collected. Common formats specifications are required to simplify users daily work and future data retrievers. Thus, including the opportunity to integrate existing information. The database should be intended not as a static archive but as a dynamic tool subjected to the innovation technology pace.

A final recommendation includes the attention that should be paid in structuring information in BACA according to a shared information management system to avoid data fragmentation and guarantee and efficient management of heterogeneous data sources.

\section{CONCLUSIONS}

The outcomes of the capacity building activities addressed four main aspects: a) assure quality and integrity of heritage records in order to guarantee information reliability (Davide Mezzino, Santana Quintero, Pei, \& Reyes Rodriguez, 2015); b) consider data longevity issues particularly in relation to the growth of digital records thus increasing long-standing problems; c) avoid data fragmentation structuring information in BACA according to a shared information management system; d) planning of heritage recording activities to organize timelines and calculate projects costs according to different documentation scopes.

These aspects have been considered along all the project timeframework. The capacity building project has not only be a technical explanation of techniques and tools but a comprehensive understanding of documentation strategies to identify the most efficient and effective solutions according to specific project requirements and needs.

\section{ACKNOWLEDGEMENTS}

The projects has been carried out in the framework of the "Documentation od Built Heritage at Muharraq for Pearls Path Project" funded by the Bahrain Authority for Culture and Antiquities (BACA). The authors wish to acknowledge and thank the support of BACA's endeavor for the conservation of Bahrain's heritage and for this outstanding opportunity to contribute to this great project.

It has been a unique opportunity to collaborate along with other BACA experts in a training aimed at improving documentation skills for conservation and preventive maintenance of built heritage.

In addition, we wish to thank the support of Noura Al Sayeh, Ahmed Aljishi, Fatima Mahammed Rafiq, Miray Hasaltun Wosisnki, Michal Wosinski and Alaa El Habashi.

We also should acknowledge the enthusiasm and participation of the attendees from BACA: Ahmed A.Nabi, Zakariya Abbas, Marwa Reyadh Alarayedh, Nailah Al Khalifa, Dalia Yusuf Abdulhameed, Fatma Yateem, and Fatma A.Nabi, which made this project successful.

\section{REFERENCES}

- Bahrain Authority for Culture and Antiquities. (n.d.). Sheikh Isa Bin Ali House. Retrieved from http://culture.gov.bh/en/visitingbahrain/destinations/Name, 10554,en.html\#.WSRNnWjytPY

- Barazzetti, L., Banfi, F., Brumana, Raffaella Gusmeroli, G., \& Previtali, Mattia Schiantarelli, G. (2015). Cloud-to-BIMto-FEM: Structural simulation with accurate historic BIM from laser scans. Simulation Modelling Practice and Theory, 57, 71-87.

- Economist Newspaper. (n.d.). Muharraq Pearling Heritage Conservation and Urban Economic Revival. Retrieved March 21, 2017, from http://jobs.economist.com/job/10786/general-procurementnotice/

- Kingdom of Bahrain Ministry of Culture \& Information. (2012). Nomination to the World Heritage List.

- Mezzino, D., Quintero, M. S., Pwint, P. M., Latt, W. T. H., \& Rellensmann, C. (2016). Technical assistance for the conservation of built heritage at bagan, Myanmar. International Archives of the Photogrammetry, Remote Sensing and Spatial Information Sciences - ISPRS Archives, 41(July), 945-952. https://doi.org/10.5194/isprsarchivesXLI-B5-945-2016

- Mezzino, D., Santana Quintero, M., Pei, W., \& Reyes Rodriguez, R. (2015). Documenting Modern Mexican Architectural Heritage for Posterity: Barragán's Casa Cristo, in Guadalajara, Mexico. In ISPRS Annals of the Photogrammetry, Remote Sensing and Spatial Information Sciences, 2015. XXV International CIPA Symposium (p. pp.199-206). Taipei, Taiwan.

- TipTopGlobe.com. (n.d.). Al Muharraq. Retrieved February 3, 2017, from http://www.tiptopglobe.com/city?n=Al Muharraq\&p $=97458$

- UNESCO. (n.d.). Pearling, Testimony of an Island Economy. Retrieved March 2, 2017, from Pearling, Testimony of an Island Economy 